\section{An Oncologist's Letter to Santa}

Dear Santa,

First, thank you for bringing me everything I wanted last year. I was really surprised to find that sparkly bracelet and red Jimmy Choo shoes under the tree! Your elves do nice work! I imagine this finds you pretty busy. You probably have a lot on your plate, and I'm sure Mrs. Claus is having a hard time keeping the elves stocked up with energy cookies while they hammer away in your workshop. I also suspect it's cold as the dickens up there. I always wonder whether that makes Rudolph's nose redder than usual. Does it?

Anyway, I want you to know that I have been very good, so I hope I can get some of what I want this year. I know you have a lot of letters to read, so I've tried to keep mine short.

First, I would like the Affordable Care Act (or whatever replacement is put in place) to get affordable again. It's pretty nice that patients with pre-existing conditions can get insurance, but its gotten too expensive. I hope you can fix that.

Second, I would like some really effective new drugs for patients with cancer that don't cost an arm and a leg. In fact, if you could do something about the cost of all drugs, it would be pretty great!

Third, I would really like some reimbursement reform so that doctors who do nonprocedural medicine can stay in business. We have lots and lots of cancer survivors who need these providers.

Next, assuming you have enough room in your sleigh, I hope you can bring some bundles of cash for doctors who are struggling to meet the Centers for Medicare \& Medicaid Services requirements like MACRA (Medicare Access and CHIP Reauthorization Act of 2015). Some practices are going to have a hard time with this and they need some help.

Finally, could you please send the Department of Health \& Human Services a message? Complying with HIPAA has become more and more ridiculous, and they really need to take another look at this. You're a pretty influential guy, so a note from you might be pretty effective. Think about it: if you break your ankle going down somebody's chimney and need to visit an emergency room down here on Christmas Eve, it would be great if your doctor at the North Pole could be contacted with a simple email rather than struggling with a "secure" envelope.

Well, that about does it for me. I hope you don't think I'm too greedy, and I promise to understand if you can't get me everything I want. In the meantime, I wish you, Mrs. Claus, all your elves, and even the reindeer all the joy and blessings this season can bring. And please take a vacation soon. I suspect you need it!

Sincerely,

$$
\text { Margaret }
$$

What do you think? Please e-mail correspondence (include contact information) to JNCCN@nccn.org.

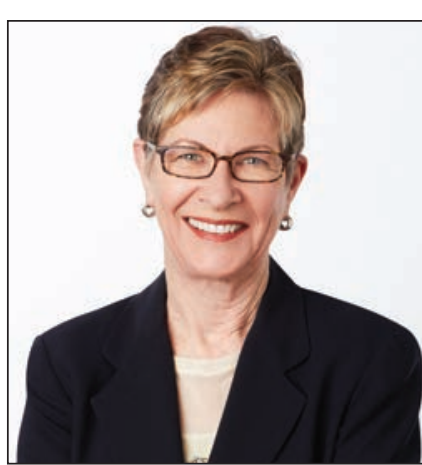

Margaret Tempero, MD

Margaret Tempero, MD, is a Professor of Medicine and Director of the UCSF Pancreas Center and editor-in-chief of JNCCN. Her research career has focused on pancreatic ductal adenocarcinoma, especially in the area of investigational therapeutics. Dr. Tempero has served on the ASCO Board of Directors and as ASCO President. She currently serves on the ASCO Conquer Cancer Foundation Board. She codirected the AACR/ASCO Methods in Clinical Cancer Research and taught this course and similar courses in Europe and Australia. She was founding Chair of the NCl Clinical Oncology Study Section and served as a member and Chair of the NCl Board of Scientific Counselors Subcommittee A. She is a member of the Scientific Steering Committee and Chair of the Clinical and Translational Study Section for the Cancer Prevention \& Research Institute of Texas. She is or has been on the Scientific Advisory Boards of the Lustgarten Foundation, the Pancreatic Cancer Action Network, the V Foundation, The Alberta Canada Cancer Board, and the EORTC. She served as a member of the Oncology Drug Advisory Committee for the FDA. She has served as Deputy Director and Interim Director for the UNMC Eppley Cancer Center. She is Chief Emeritus of the Division of Medical Oncology at UCSF and served as the founding Deputy Director and Director of Research Programs at the UCSF Helen Diller Family Comprehensive Cancer Center.

The ideas and viewpoints expressed in this editorial are those of the author and do not necessarily represent any policy, position, or program of NCCN. 